\title{
Conventional open versus hybrid aortic arch repair: a meta- analysis of propensity-matched studies
}

\author{
Yong Zhan, Hannah Kooperkamp, Serena Lofftus, Daniel McGrath, Masashi Kawabori, Frederick Y. Chen \\ Division of Cardiac Surgery, Tufts Medical Center, Tufts University School of Medicine, Boston, MA, USA \\ Contributions: (I) Conception and design: Y Zhan; (II) Administrative support: FY Chen; (III) Provision of study materials or patients: None; (IV) \\ Collection and assembly of data: Y Zhan, H Kooperkamp, S Lofftus; (V) Data analysis and interpretation: Y Zhan, H Kooperkamp, D McGrath, M \\ Kawabori; (VI) Manuscript writing: All authors; (VII) Final approval of manuscript: All authors. \\ Correspondence to: Yong Zhan, MD. Division of Cardiac Surgery, Tufts Medical Center, 800 Washington Street, \#266, Boston, MA 02111, USA. \\ Email: yzhan@tuftsmedicalcenter.org.
}

\begin{abstract}
Background: Comparison of conventional (open) surgical versus hybrid aortic arch repair remains debatable. While the majority of previous comparative studies including meta-analyses contained primarily risk-unadjusted cohorts, those focusing on propensity-matched comparisons were limited by their small sample size. We aimed to compare outcomes of these two approaches through an up-to-date search and meta-analysis of the best evidence currently available in the literature.

Methods: The PubMed/MEDLINE, EMBASE, and Cochrane library from inception to September 2019 were searched to identify articles reporting propensity-score matching data on open versus hybrid aortic arch repair. Patients' baseline characteristics and clinical outcomes were extracted from the articles and pooled for analysis. Heterogeneity and biases were assessed among the included studies.

Results: Five studies, including a total of 378 patients (189 pairs), were included in the study. The two groups were similar in patients' baseline characteristics. Stroke rate favoured the open group [2.1\% versus $14.3 \%$, OR $0.18(0.07,0.46), \mathrm{P}=0.0004, \mathrm{I}^{2}=0 \%$ ]. There was no significant difference between the two groups with regard to paraplegia. The hybrid group had numerically higher short-term mortality, but lower rate of acute renal failure requiring dialysis. There was a statistically significant difference between the midterm survivals of the open and hybrid groups, with lower pooled mortality seen for the open group at 1-year and 2-years $(\mathrm{P}=0.02)$.

Conclusions: Open and hybrid repairs do not offer equivalent outcomes. Compared with hybrid aortic arch repair, conventional surgical aortic repair could be associated with favourable outcomes including postoperative stroke. Hybrid repair does not appear to provide better survival. Operative approaches should be carefully selected in treating aortic arch pathology.
\end{abstract}

Keywords: Aortic arch; debranching; hybrid; meta-analysis

Submitted Jan 29, 2021. Accepted for publication Jul 02, 2021.

doi: $10.21037 /$ jtd-21-183

View this article at: https://dx.doi.org/10.21037/jtd-21-183

\section{Introduction}

Conventional total aortic arch repair (TAR) is considered the standard surgical approach in the treatment of aortic arch pathology, and the associated surgical outcomes continue to improve owing to technical refinement in surgery and advances in perioperative care $(1,2)$. However, due to the nature and extent of the surgery, this approach is still associated with considerable mortality and morbidity. Endovascular aortic repair has emerged as a promising therapy for complex aortic disease. With advances in technologies, its applicability has been evolving to include aortic arch pathology, and the role of the open approach is being challenged as the preferred surgery for patients in the 
category (3-5).

Total endovascular repair of the aortic arch is technically demanding; thus, it has not been the mainstay in the management of aortic arch aneurysms $(4,5)$. In the interim, a combined open surgical aortic arch debranching and endovascular repair approach, so called hybrid surgery, provides another venue for the current aortic surgery practice (6). Although a paradigm shift in the management of aortic arch diseases may be anticipated in the future, strong evidence is still lacking with respect to the selection of these surgical approaches.

In the past decade, there has been an increasing number of reports in the literature describing the procedural success and excellent clinical outcomes of both open and hybrid approaches to aortic arch repair (7-13). Previous systemic reviews and meta-analyses of comparative studies revealed either no differences or conflicting outcomes between the two approaches (14-16). In these studies, the hybrid cohorts had different risk profiles, as the hybrid approach is generally utilized as an alternative in high-risk patients or those deemed not suitable for the open approach (6-8). While there is no randomized controlled trial comparing the two approaches at this time, it is imperative to identify the best evidence for this subject. Therefore, we performed a meta-analysis of comparative studies on conventional surgical (open) and hybrid repairs using propensity-matched methodology, aiming to provide insight on the decisionmaking in the aortic arch surgery.

We present the following article in accordance with the PRISMA reporting checklist (available at https://dx.doi. org/10.21037/jtd-21-183).

\section{Methods}

\section{Search strategy}

An electronic search of the PubMed/MEDLINE, EMBASE, and Cochrane Library database from the inception to September 2019 was performed to identify full peer-review articles in English comparing open and hybrid aortic arch repairs using the propensity-matching. Search terms included "aortic arch" OR "aortic arch repair" AND "propensity" OR "match" OR "matched" AND "hybrid" OR "debranching". Two researchers (HK and SL) conducted the search independently, and discrepancy between reviewers was resolved by discussion (YZ, HK and SL) until a consensus was reached. A manual search of additional articles was also performed in the references of relevant articles and review papers. This meta-analysis followed the Preferred Reporting Items for Systematic Reviews and Meta Analyses (PRISMA) guidelines (17).

\section{Study selection and quality assessment}

Studies were considered eligible if they met all of the following criteria: (I) randomized controlled trials or observational studies; (II) studies contain propensitymatched data; (III) patient demographics are reported; (IV) sufficient data of outcomes for both approaches. Studies were excluded if there is insufficient or inadequate data for analysis, if the study is a case report or review, or if there is duplicate or overlapping data including the studies from the same institutions and contributed by the authors who participated in other studies selected for this meta-analysis. A quality assessment of each selected study was conducted using the Cochrane risk-of-bias tool and the NewcastleOttawa Scale $(17,18)$.

\section{Definition of open versus bybrid surgery}

Open arch repair requires cardiopulmonary bypass and cooling of patients for hypothermic circulatory arrest (HCA). Either antegrade or retrograde cerebral perfusion is administered. Aortic arch reconstruction is performed in island patch configuration or separate reimplantation of the arch branches. We chose to exclude studies where the frozen elephant trunk (FET) procedure routinely constitutes TAR, as FET is considered as a type of hybrid surgery (6).

Hybrid surgery includes anatomical or extra-anatomical debranching of the arch branches. Anatomical debranching involves sternotomy, and transection and reimplantation of three arch vessels to the proximal ascending aorta typically via a trifurcate graft for a zone 0 repair. The ascending aorta could be either native (type I) or replaced by a Dacron graft (type II). Extra-anatomical debranching involves left carotid-left subclavian artery bypass for zone 2 proximal landing of the endograft, or left carotid-right carotid/ subclavian artery bypass and left subclavian-carotid artery bypass for zone 1 proximal landing. Endograft deployment is achieved in either antegrade or retrograde fashion. The proximal subclavian artery is transected or occluded endovascularly to prevent endoleak. TAR with or without FET were previously compared in meta-analysis $(19,20)$; therefore, this comparison was not the focus of the present 


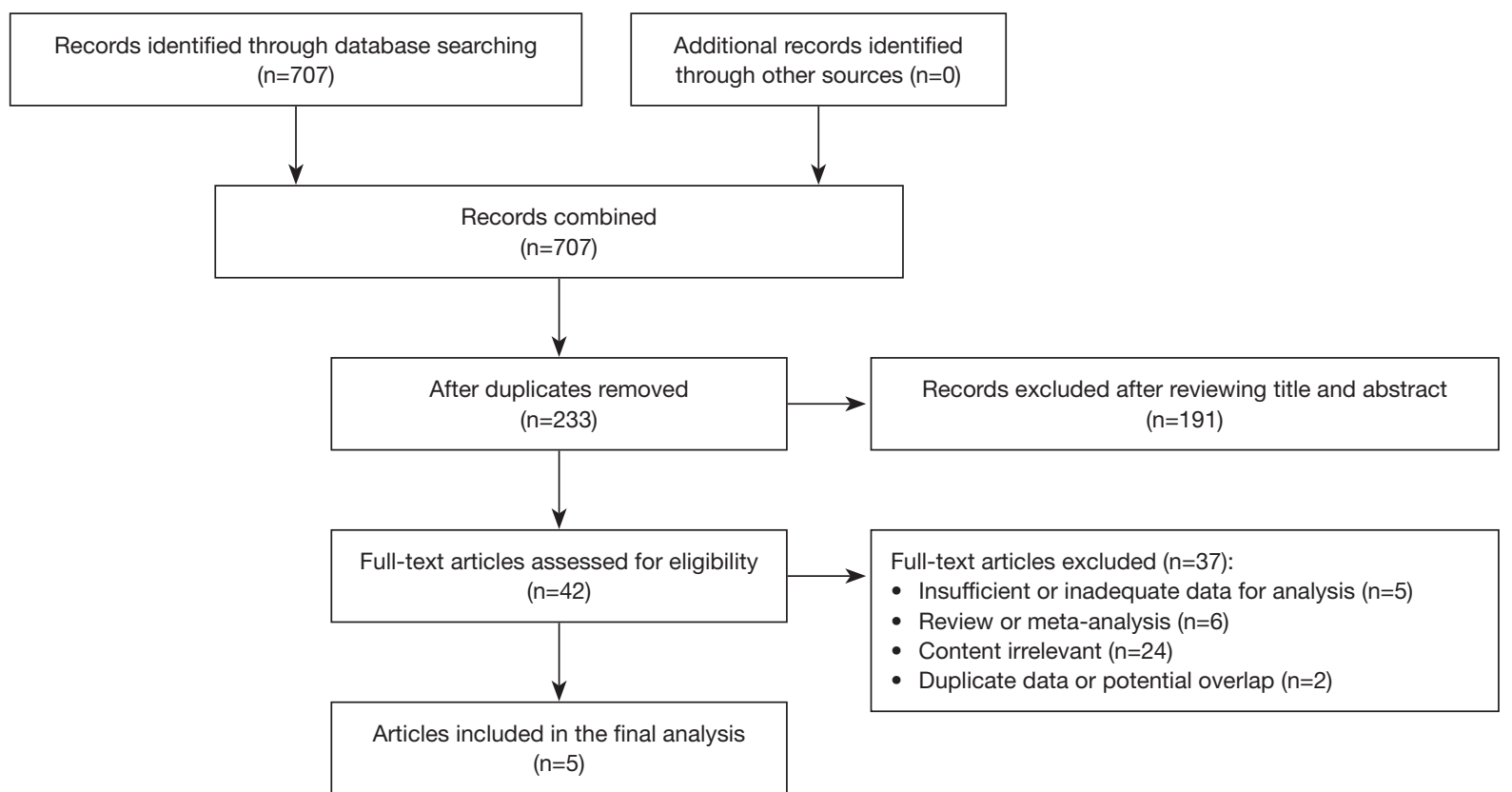

Figure 1 Summary of the systematic search and identification of eligible studies (PRISMA flow diagram). PRISMA, Preferred Reporting Items for Systematic Reviews and Meta Analyses.

meta-analysis.

\section{Data extraction}

Patients' baseline characteristics, procedural outcomes, and clinical outcomes were extracted from the articles and pooled for analysis. Data on the open approach and hybrid approach were grouped separately. Mid-term survival rates were either extracted directly from articles if reported or estimated from Kaplan-Meier curves. Kaplan-Meier curves were digitalized using the DigitizeIt software, and survival rates of each individual cohort at 1-and 2-year were identified. Mortality rates in the studies at each time point were estimated, then pooled and compared between the open and hybrid groups.

\section{Statistical analysis}

Continuous variables are presented as means \pm standard deviation (SD) and categoric variables are presented as percentages. Some studies reported median and interquartile range, which were converted to mean and $\mathrm{SD}$; median is considered as mean, and SD is calculated by dividing the interquartile range by 1.35 . Events rates in studies reporting zero event rates were approximated as 1 in
$4 \times$ sample size, so these studies could be included in pooled estimates. The Cochrane Collaboration Review Manager 5.3 software was used for meta-analysis. For forest plots, the odds ratio (OR) was used as a summary statistic, and $95 \%$ confidence intervals based on Mantel-Haenszel (M$\mathrm{H}) \chi^{2}$ were estimated to compare outcomes. Both fixed- and random-effects models were tested. The results using the random-effects model were presented. The heterogeneity of outcomes between the studies was determined using the $\chi^{2}$ test. $\mathrm{I}^{2}$ statistic and degree of freedom (df) were calculated to estimate variation across studies. We defined an $\mathrm{I}^{2}<25 \%, 25-50 \%$, and $>50 \%$ as low, moderate, and high heterogeneity, respectively. Funnel plots were used to assess publication bias for the outcomes. Statistical significance for hypothesis testing was set at the 0.05 level.

\section{Results}

\section{Literature search}

A total of 707 articles were identified through our initial literature search. After duplicates were removed, and titles and abstracts reviewed, 42 articles were assessed in full-text. Of these, a further 37 studies were excluded, and 5 studies (9-13) met the inclusion criteria for meta-analysis (Figure 1). An overview of these studies is summarized in Table 1. 
Table 1 Summary of studies included in the meta-analysis

\begin{tabular}{|c|c|c|c|c|c|c|}
\hline Study & $\begin{array}{c}\text { Year } \\
\text { published }\end{array}$ & Study period & $\begin{array}{c}\text { Open (No. of } \\
\text { matched/total No.) }\end{array}$ & $\begin{array}{c}\text { Hybrid (No. of } \\
\text { matched/total No.) }\end{array}$ & Type of study & $\begin{array}{l}\text { Newcastle- } \\
\text { Ottowa score }\end{array}$ \\
\hline Hiraoka (12) & 2017 & 2006-2016 & $43 / 337$ & $43 / 58$ & Retrospective study & $9 / 9$ \\
\hline Joo (13) & 2019 & 2002-2017 & $48 / 174$ & $48 / 64$ & $\begin{array}{c}\text { Prospective data, retrospective } \\
\text { review }\end{array}$ & $9 / 9$ \\
\hline Tokuda (11) & 2016 & 2002-2014 & $38 / 124$ & $38 / 58$ & Retrospective study & $8 / 9$ \\
\hline
\end{tabular}

Table 2 Pooled patient characteristics

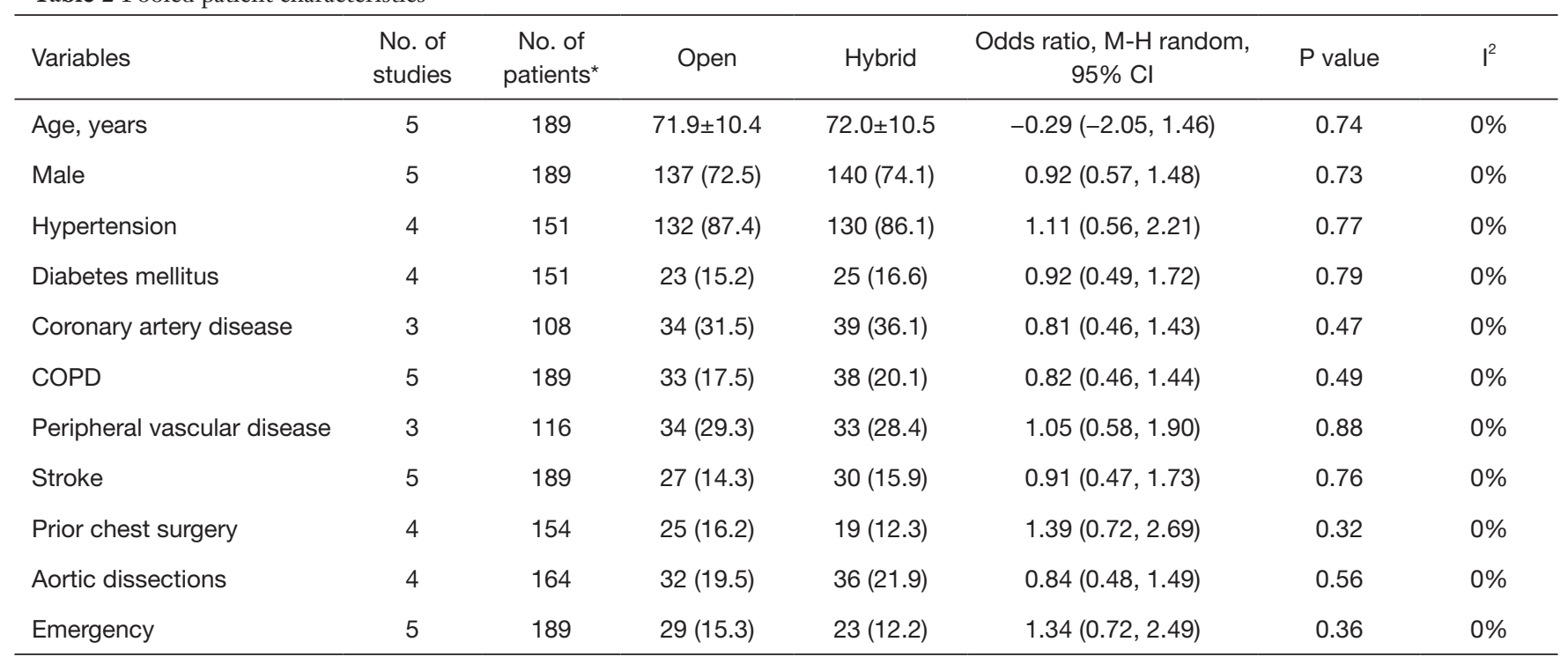

${ }^{*}$, of each group. Values are number, percentage (in parentheses), and mean \pm SD. COPD, chronic obstructive pulmonary disease.

All 5 studies contain propensity-matched data comparing open and hybrid aortic arch repairs, and all were singlecentre retrospective studies with sample sizes ranging from 25 to 48 pairs. Quality assessment of each study was performed (Table S1). These studies were of good quality and acceptable for meta-analysis with an average score of 8.4 using the Newcastle-Ottawa scale. Of the included studies, no randomized controlled trials were identified.

\section{Patient demographics}

Overall, the 5 studies comprising this meta-analysis include a total of 378 patients, with 189 patients in each group. Patient characteristics from these studies were extracted and pooled for analysis (Table S2). Comparison of the demographic data showed that the open and hybrid groups were similar with regard to age, male gender, hypertension, diabetes, coronary artery disease, chronic obstructive pulmonary disease, peripheral vascular disease, stroke, prior chest surgery, aortic dissections, and status of emergent surgery (Table 2).

\section{Operative techniques}

All patients in the open group underwent TAR using moderate or deep HCA at $21-28{ }^{\circ} \mathrm{C}$. Antegrade cerebral perfusion was uniformly utilized, and bilateral perfusion was preferred and conducted in the vast majority of case (9-12). Only one study involved FET as an adjunct procedure in $9 \%$ $(26 / 274)$ of their entire cohort undergoing TAR (10). 
Table 3 Comparison of patient outcomes between open and hybrid groups

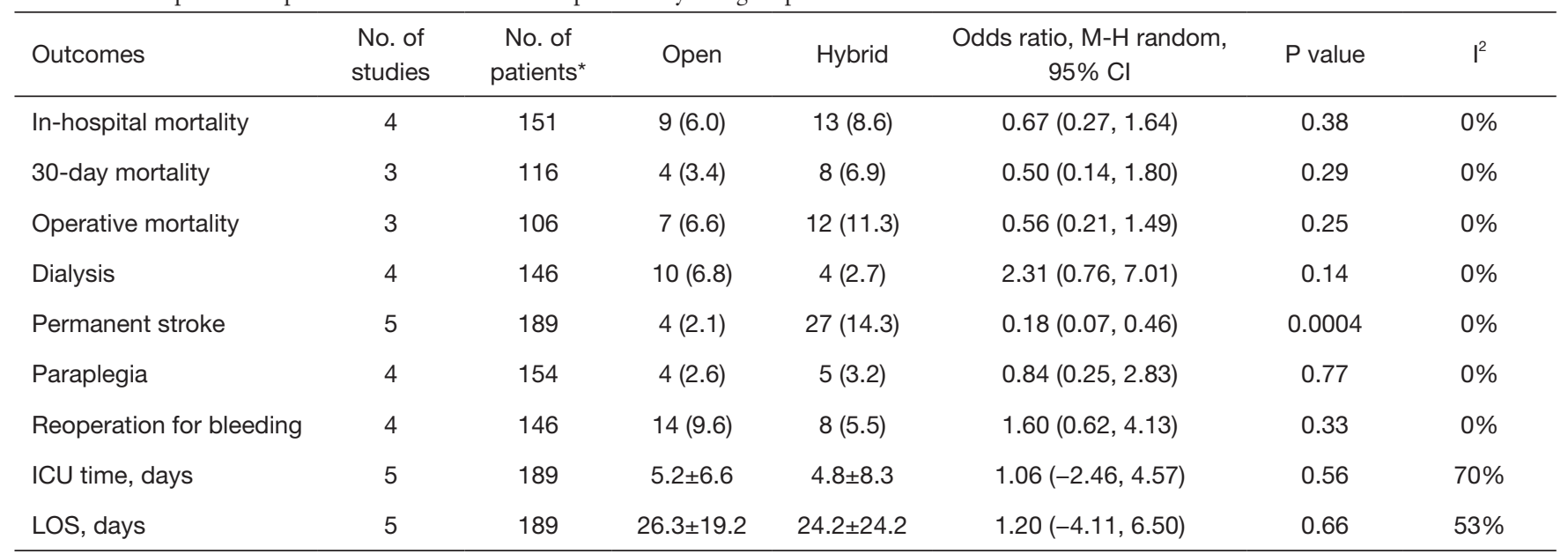

*, in each group. Values are number, percentage (in parentheses), and mean \pm SD. Cl, confidence interval; ICU, intensive care unit; LOS, length of stay; M-H, Mantel-Haenszel.

In these articles, the detail of the operative technique for the hybrid group was not specified for the propensitymatched cohorts in each individual article, instead it was described for the whole patient population. In two studies, aortic arch debranching via sternotomy (anatomical debranching) where the supra-aortic branches were rerouted to the proximal native ascending aorta or aortic graft was the default operation for their entire hybrid cohorts $(10,13)$. Two studies $(9,12)$ also included extra-anatomical debranching of supra-aortic arch vessels $(76 \%$ and $84 \%$, respectively). Twenty-seven cases $(14.7 \%)$ in the hybrid group required cardiopulmonary bypass (Table S3). Twelve (4.4\%) of 275 patients (the entire population of the hybrid group prior to propensity matching) underwent a modified type 3 hybrid aortic repair (insertion of endografts into the aorta under HCA without TAR) (11).

\section{Meta-analysis of outcomes}

\section{Early mortality}

Incidences of in-hospital mortality were provided by 4 studies (Table 3, Figure 2). Data were pooled and showed that the two groups had comparable in-hospital mortality (6.0\% vs. $8.6 \%$; OR 0.67 ; $95 \%$ CI: $0.27-1.64 ; \mathrm{P}=0.38$ ) with no heterogeneity $\left(\mathrm{I}^{2}=0 \%\right)$. Data on 30 -day mortality and operative mortality were reported in 3 articles, respectively. There were no significant differences observed between the two groups on 30 -day mortality (3.4\% vs. $6.9 \%$; OR 0.50 ; 95\% CI: $0.14-1.80 ; \mathrm{P}=0.29)$ or operative mortality $(6.6 \%$ vs.
11.3\%; OR 0.56; 95\% CI: 0.21-1.49; $\mathrm{P}=0.25$ ) both without heterogeneity $\left(\mathrm{I}^{2}=0 \%\right)$ (Table 3).

\section{Permanent stroke}

All 5 studies reported data on permanent stroke. A significant difference was seen between the two groups favouring the open group (2.1\% vs. $14.3 \%$; OR 0.18 ; 95\% CI: $0.07-0.46$; $\mathrm{P}=0.0004)$ with no heterogeneity $\left(\mathrm{I}^{2}=0 \%\right)$ (Figure 2).

\section{Mid-term mortality}

The 1- and 2-year mortality rates from all five articles either reported by individual studies or identified from the Kaplan-Meier curves were pooled and analyzed (Table 4). At 1 year, the hybrid group had significantly higher mortality compared to the open group (OR 0.42; 95\% CI: $0.20-0.88$; $\mathrm{P}=0.02)$ with no heterogeneity $\left(\mathrm{I}^{2}=0 \%\right)$. This trend was shared by the result at 2-years (OR 0.48 ; $95 \%$ CI: 0.26-0.88; $\mathrm{P}=0.02)$ with no heterogeneity $\left(\mathrm{I}^{2}=0 \%\right)$.

\section{Other outcomes}

Four studies reported paraplegia rates (10-13). We found no statistical difference between the two groups $(2.6 \%$ vs. $3.2 \%$; OR $0.84 ; 95 \% \mathrm{CI}: 0.25-2.83 ; \mathrm{P}=0.77$ ) with no heterogeneity $\left(\mathrm{I}^{2}=0 \%\right)$ (Table 3, Figure S1). Furthermore, our pooled results did not reveal significant difference with regard to new dialysis requirement, although the rate for the open group was numerically higher $(6.8 \%$ vs. $2.7 \%$; OR 2.31, 95\% CI: 0.76-7.01; $\mathrm{P}=0.14$ ) with no heterogeneity $\left(\mathrm{I}^{2}=0 \%\right.$ ) (Figure 2 ). The rate of reoperation 

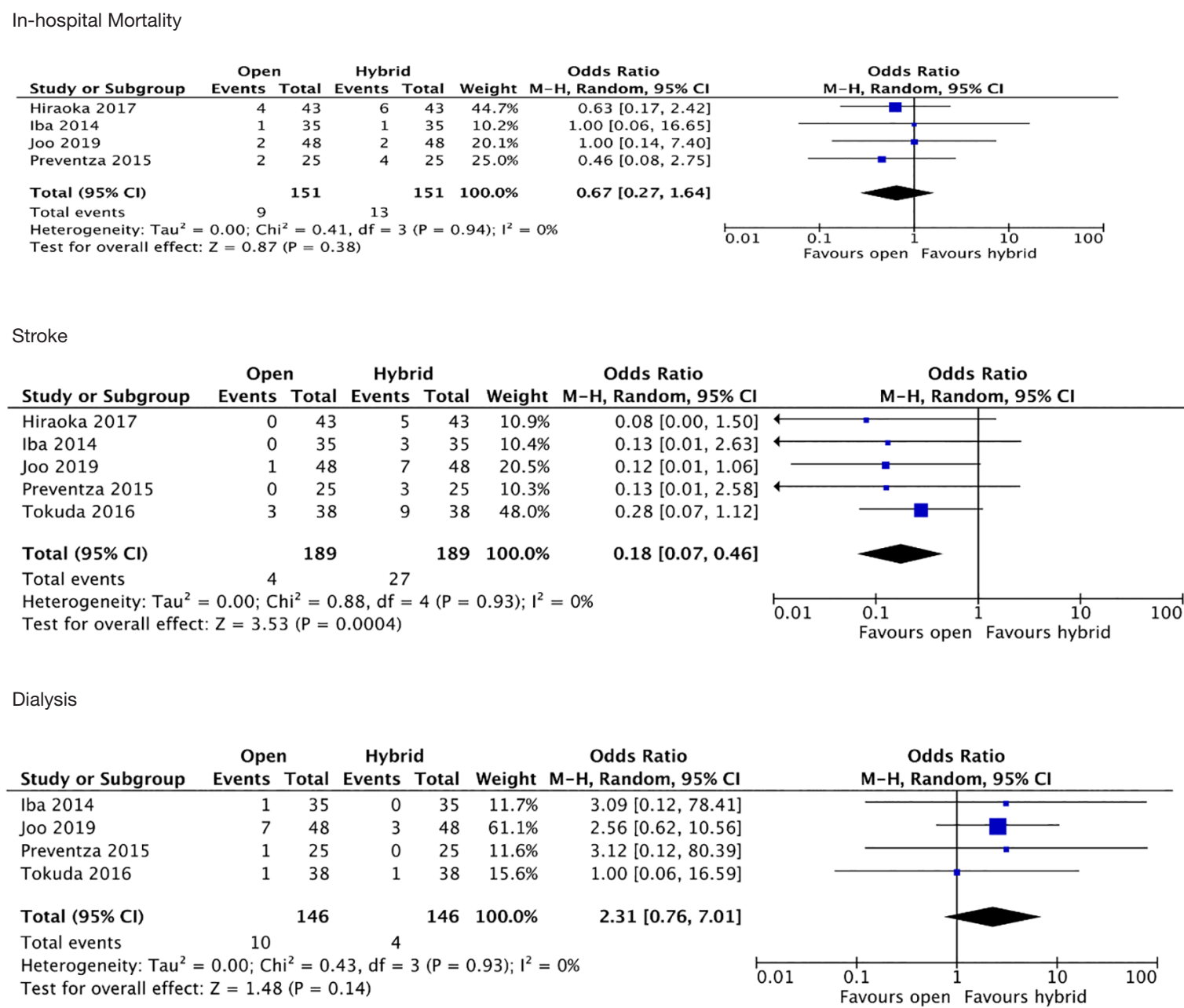

Figure 2 Forest plots for the comparison of outcomes of patients undergoing open versus hybrid aortic arch repair.

Table 4 Comparison of Mid-term Mortality between Open and Hybrid Groups

\begin{tabular}{|c|c|c|c|c|c|c|}
\hline Mortality & No. of studies & \multicolumn{3}{|c|}{ Heterogeneity } & \multicolumn{2}{|c|}{$\mathrm{M}-\mathrm{H}$, random-effect } \\
\hline 1 year & 5 & 1.42 & $4(0.84)$ & 0 & $0.42(0.20,0.88)$ & $2.31(0.02)$ \\
\hline 2 years & 5 & 1.37 & $4(0.85)$ & 0 & $0.48(0.26,0.88)$ & $2.38(0.02)$ \\
\hline
\end{tabular}

$\mathrm{Cl}$, confidence interval; M-H, Mantel-Haenszel.

mainly for bleeding was also numerically higher for the open group compared with the hybrid group $(9.6 \%$ versus $5.5 \%$; OR $1.60,95 \% \mathrm{CI}: 0.62-4.13 ; \mathrm{P}=0.33$ ) with no heterogeneity $\left(\mathrm{I}^{2}=0 \%\right)$ (Table 3). Intensive care unit (ICU) time and length of stay (LOS) was provided by all 5 articles, and pooled results showed no significant differences (ICU time: $5.2 \pm 6.6$ versus $4.8 \pm 8.3$ days; OR
1.06, 95\% CI: $-2.46-4.57 ; \mathrm{P}=0.56$ and LOS: $26.3 \pm 19.2$ versus $24.2 \pm 24.2$ days; OR 1.20, 95\% CI: $-4.11-6.50$; $\mathrm{P}=0.66$ ) both with high heterogeneity (Table 3).

\section{Discussion}

Open surgical repair for aortic arch diseases remains 
challenging in the current era despite continuous improvement in surgical outcomes. While total endovascular repair is currently still evolving, hybrid approaches have become increasingly popular in recent years. However, whether it is superior over the conventional TAR has yet to be validated. Our metaanalysis revealed that open surgical and hybrid approaches did not differ in the majority of early outcomes except for stroke. The finding that the open group had a lower incidence of permanent stroke seemed counterintuitive, as TAR involves HCA, which is inheritably associated with increased risk for stroke. There is no doubt that cerebral perfusion particularly in antegrade fashion, as advocated by many in recent years, has positive effects on cerebral protection $(21,22)$. A hybrid repair avoids HCA, but manipulation of the aortic arch with wires and endografts could theoretically contribute to an increase in embolic stroke. Coverage of arch branches with or without revascularization could also be relevant to perioperative cerebral accidents. Although hybrid procedures are utilized in hope to reduce operative morbidity, the increase in stroke risk appears to undermine the perceived benefit from this approach.

Hybrid approaches that involve coverage of intercostal vessels with endografts could expose patients to increased risk of spinal ischemia. In our meta-analysis, the open and hybrid groups had similar incidences of paraplegia. The overall incidence of paraplegia in the hybrid group (3.2\%) was in accordance with those reported in the literature on endovascular repair for descending aortic aneurysms or dissections $(23,24)$. The results of the studies included in our meta-analysis reflect recent advances regarding this subject where avoiding extensive coverage of the descending aorta is advocated. The FET procedure can be performed as an adjunct to TAR, although by definition this is a hybrid approach (6). For the purpose of a fair comparison, we restricted the open repair group to studies that involve limited endovascular repair components. Therefore, studies that utilized a combination of TAR and FET as the default surgical approach were excluded from our meta-analysis. As a result, only one study included the FET procedure in less than $10 \%$ of their TAR cohort (10). A reduced incidence of spinal ischemia was noted for TAR in a previous meta-analysis comparing the open and hybrid approaches (16). Since most of the surgeries in their hybrid group were FET procedures, the differences in our inclusion criteria could explain the controversy in this regard. With optimal surgical techniques, hybrid aortic arch repair does not appear to be associated with increased risk of paraplegia, although it is still controversial particularly on FET in the setting of acute type A aortic dissection $(19,20,25)$.

Previous meta-analyses revealed that the open and hybrid approaches could be associated with comparable early outcomes and late survivals despite that patient-risk profiles were either not stratified or appeared different (14-16). Our meta-analysis was focused on propensitymatched comparative studies in the literature. Among the 5 studies selected for this meta-analysis, only one study found statistical significance between open and hybrid cohorts in terms of survival (13), whereas numerically lower survivals were found among hybrid cohorts in 3 other studies $(9,11,12)$. Our pooled data from Kaplan-Meier curves revealed a higher mid-term (1-2 year) mortality with the hybrid group. Chakos and colleagues found that longterm survival outcomes as relate to the open and hybrid approaches were inconclusive (16). With knowledge of comparable short-term survivals (operative, in-hospital, and 30-day mortalities) between the two groups, we hypothesized that this favourable trend with regard to midterm survival toward the open group might be related to patient selection bias, since hybrid approaches are often chosen for patients not good candidates for open repair (6-8). Although the baseline characteristics of patients were homogenous between the two groups, as only studies using propensity-matching methodology were included in our meta-analysis, such a bias could still be present and potentially lead to the higher mortality with the hybrid group due to risk factors not captured, such as frailty and/or malignancy. The decreased mid-term survival for the hybrid repair group could be due to increased reinterventions associated with endografts as well; however, this could not be extrapolated from the current data. In 4 of the 5 studies, increased aortic interventions or aortic events were reported during follow-up (9,11-13), but it was impossible to perform meta-analysis due to heterogenous data reporting. Nevertheless, the hybrid approach does not appear to provide better survival. Our data suggest that while hybrid approaches are valid options for aortic arch pathologies, it should be used judiciously.

The success of aortic arch surgery relies on careful selection of approaches. Choosing a hybrid approach can be based on individual patient's characteristics and contingency relevant to patient's anatomy. While there is no good evidence to support hybrid repair as a preferred approach, it remains as alternative to open repair. A randomized trial or 
a data registry would potentially provide validation.

\section{Study limitations}

The major limitation of our study stems from the small number of studies qualified for the meta-analysis. In addition, the studies included are all single-centre retrospective studies. Although these comparative studies are all propensity-matched, there is still a lack of standardization in data reporting, including baseline characteristic and outcome measures. Due to the limited number of articles, it was impossible to stratify the studies based on operative approaches, for example, anatomical versus extra-anatomical debranching, which could be associated with different outcomes. Meta-analysis enhanced statistical power, but still could not detect statistical significance in some study endpoints. As there was no randomisation of surgical approaches, selection bias could be present (Figure S2). There could also be inherent publication bias with the present meta-analysis due to the nature of retrospective studies that tend to report favourable outcomes (Figure S3).

\section{Conclusions}

We performed a meta-analysis comparing the hybrid and conventional open surgical approaches to aortic arch repair, and our results show favourable outcomes associated with open approach in respect to postoperative stroke. Current evidence suggests that open and hybrid repairs are not associated with equivalent outcomes, and surgical approaches to aortic arch diseases should be carefully selected.

\section{Acknowledgments}

Funding: None.

\section{Footnote}

Reporting Checklist: The authors have completed the PRISMA reporting checklist. Available at https://dx.doi. org/10.21037/jtd-21-183

Conflicts of Interest: All authors have completed the ICMJE uniform disclosure form (available at https://dx.doi. org/10.21037/jtd-21-183). The authors have no conflicts of interest to declare.
Ethical Statement: The authors are accountable for all aspects of the work in ensuring that questions related to the accuracy or integrity of any part of the work are appropriately investigated and resolved.

Open Access Statement: This is an Open Access article distributed in accordance with the Creative Commons Attribution-NonCommercial-NoDerivs 4.0 International License (CC BY-NC-ND 4.0), which permits the noncommercial replication and distribution of the article with the strict proviso that no changes or edits are made and the original work is properly cited (including links to both the formal publication through the relevant DOI and the license). See: https://creativecommons.org/licenses/by-nc-nd/4.0/.

\section{References}

1. Sundt TM 3rd, Orszulak TA, Cook DJ, et al. Improving results of open arch replacement. Ann Thorac Surg 2008;86:787-96; discussion 787-96.

2. Okada K, Omura A, Kano H, et al. Recent advancements of total aortic arch replacement. J Thorac Cardiovasc Surg 2012;144:139-45.

3. Desai ND, Roselli EE. Complex aortic arch surgery. Ann Cardiothorac Surg 2018;7:318.

4. Maurel B, Mastracci TM, Spear R, et al. Branched and fenestrated options to treat aortic arch aneurysms. J Cardiovasc Surg (Torino) 2016;57:686-97.

5. Czerny M, Rylski B, Morlock J, et al. Orthotopic branched endovascular aortic arch repair in patients who cannot undergo classical surgery. Eur J Cardiothorac Surg 2018;53:1007-12.

6. Szeto WY, Bavaria JE. Hybrid repair of aortic arch aneurysms: combined open arch reconstruction and endovascular repair. Semin Thorac Cardiovasc Surg 2009;21:347-54.

7. Milewski RK, Szeto WY, Pochettino A, et al. Have hybrid procedures replaced open aortic arch reconstruction in high-risk patients? A comparative study of elective open arch debranching with endovascular stent graft placement and conventional elective open total and distal aortic arch reconstruction. J Thorac Cardiovasc Surg 2010;140:590-7.

8. Sood V, Patel HJ, Williams DM, et al. Open and endovascular repair of the nontraumatic isolated aortic arch aneurysm. J Vasc Surg 2014;60:57-63.

9. Iba $\mathrm{Y}$, Minatoya $\mathrm{K}$, Matsuda $\mathrm{H}$, et al. How should aortic arch aneurysms be treated in the endovascular aortic repair era? A risk-adjusted comparison between open and hybrid 
arch repair using propensity score-matching analysis. Eur J Cardiothorac Surg 2014;46:32-9.

10. Preventza O, Garcia A, Cooley DA, et al. Total aortic arch replacement: A comparative study of zone 0 hybrid arch exclusion versus traditional open repair. J Thorac Cardiovasc Surg 2015;150:1591-8; discussion 1598-600.

11. Tokuda Y, Oshima H, Narita Y, et al. Hybrid versus open repair of aortic arch aneurysms: comparison of postoperative and mid-term outcomes with a propensity score-matching analysis. Eur J Cardiothorac Surg 2016;49:149-56.

12. Hiraoka A, Chikazawa G, Totsugawa T, et al. Objective analysis of midterm outcomes of conventional and hybrid aortic arch repair by propensity-score matching. J Thorac Cardiovasc Surg 2017;154:100-106.e1.

13. Joo HC, Youn YN, Kim JH, et al. Conventional Open Versus Hybrid Arch Repair of Aortic Arch Disease: Early and Long-Term Outcomes. Ann Thorac Surg 2019;107:1380-8.

14. Benedetto U, Melina G, Angeloni E, et al. Current results of open total arch replacement versus hybrid thoracic endovascular aortic repair for aortic arch aneurysm: a meta-analysis of comparative studies. J Thorac Cardiovasc Surg 2013;145:305-6.

15. Miao L, Song L, Sun SK, et al. Meta-analysis of open surgical repair versus hybrid arch repair for aortic arch aneurysm. Interact Cardiovasc Thorac Surg 2017;24:34-40.

16. Chakos A, Jbara D, Yan TD, et al. Long-term survival and related outcomes for hybrid versus traditional arch repair-a meta-analysis. Ann Cardiothorac Surg 2018;7:319-27.

17. Moher D, Liberati A, Tetzlaff J, et al. Preferred reporting items for systematic reviews and meta-analyses: the PRISMA statement. BMJ 2009;339:b2535.

Cite this article as: Zhan Y, Kooperkamp H, Lofftus S, McGrath D, Kawabori M, Chen FY. Conventional open versus hybrid aortic arch repair: a meta-analysis of propensity-matched studies. J Thorac Dis 2021;13(8):4714-4722. doi: 10.21037/jtd-21183
18. Wells GA, Shea JB, O'Connell D, et al. The NewcastleOttawa Scale (NOS) for assessing the quality of nonrandomized studies in meta-analyses. Ottawa, Canada: The Ottawa Hospital Research Institute; 2018. Available online: http://www.ohri.ca/programs/clinical_ epidemiology/oxford.asp

19. Hanif H, Dubois L, Ouzounian M, et al. Aortic Arch Reconstructive Surgery With Conventional Techniques vs Frozen Elephant Trunk: A Systematic Review and MetaAnalysis. Can J Cardiol 2018;34:262-73.

20. Settepani F, Cappai A, Basciu A, et al. Hybrid Versus Conventional Treatment of Acute Type A Aortic Dissection. J Card Surg 2015;30:707-13.

21. Spielvogel D, Strauch JT, Minanov OP, et al. Aortic arch replacement using a trifurcated graft and selective cerebral antegrade perfusion. Ann Thorac Surg 2002;74:S1810-4; discussion S1825-32.

22. Okita Y, Okada K, Omura A, et al. Surgical techniques of total arch replacement using selective antegrade cerebral perfusion. Ann Cardiothorac Surg 2013;2:222-8.

23. Dijkstra ML, Vainas T, Zeebregts CJ, et al. Editor's Choice - Spinal Cord Ischaemia in Endovascular Thoracic and Thoraco-abdominal Aortic Repair: Review of Preventive Strategies. Eur J Vasc Endovasc Surg 2018;55:829-41.

24. Czerny M, Eggebrecht H, Sodeck G, et al. Mechanisms of symptomatic spinal cord ischemia after TEVAR: insights from the European Registry of Endovascular Aortic Repair Complications (EuREC). J Endovasc Ther 2012;19:37-43.

25. Poon SS, Tian DH, Yan T, et al. Frozen elephant trunk does not increase incidence of paraplegia in patients with acute type A aortic dissection. J Thorac Cardiovasc Surg 2020;159:1189-1196.e1. 


\section{Supplementary}

Table S1 Newcastle-Ottawa scale of included studies

\begin{tabular}{|c|c|c|c|c|c|c|c|c|c|}
\hline Study & $\begin{array}{l}\text { Representative of } \\
\text { exposed cohort }\end{array}$ & $\begin{array}{l}\text { Selection of non- } \\
\text { exposed cohort }\end{array}$ & $\begin{array}{c}\text { Ascertainment of } \\
\text { exposure }\end{array}$ & $\begin{array}{l}\text { Outcome not present } \\
\text { at start of study }\end{array}$ & Comparability & $\begin{array}{l}\text { Assessment of } \\
\text { outcomes }\end{array}$ & $\begin{array}{l}\text { Length of } \\
\text { follow up }\end{array}$ & $\begin{array}{l}\text { Adequacy of } \\
\text { follow up }\end{array}$ & Total \\
\hline Hiraoka & * & * & * & * & ** & * & * & * & 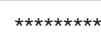 \\
\hline Iba & * & * & * & * & $* *$ & * & & * & 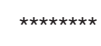 \\
\hline Joo & * & * & * & * & ** & * & * & * & 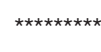 \\
\hline Preventza & * & * & * & * & ** & * & & * & 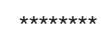 \\
\hline Tokuda & * & * & * & * & ** & * & & * & 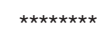 \\
\hline
\end{tabular}

*, indicates a point awarded in each category of the Newcastle-Ottawa scale.

Table S2 Patient characteristics and outcomes

\begin{tabular}{|c|c|c|c|c|c|c|c|c|c|c|}
\hline \multirow{2}{*}{ Characteristic } & \multicolumn{2}{|c|}{ Hiraoka 2017} & \multicolumn{2}{|c|}{ Iba 2014} & \multicolumn{2}{|c|}{ Joo 2019} & \multicolumn{2}{|c|}{ Preventza 2015} & \multicolumn{2}{|c|}{ Tokuda 2016} \\
\hline & Open & Hybrid & Open & Hybrid & Open & Hybrid & Open & Hybrid & Open & Hybrid \\
\hline Population (n) & 43 & 43 & 35 & 35 & 48 & 48 & 25 & 25 & 38 & 38 \\
\hline Age (mean, SD) & $73.9 \pm 8.8$ & $73.2 \pm 10.1$ & $76.3 \pm 8.5$ & $75.7 \pm 9.3$ & $67.6 \pm 12.8$ & $67.8 \pm 12.7$ & $67.0 \pm 11.1$ & $68.0 \pm 10.4$ & $74.0 \pm 6.0$ & $75.0 \pm 6.0$ \\
\hline Male (n) & 32 & 30 & 25 & 29 & 38 & 38 & 12 & 11 & 30 & 32 \\
\hline Hypertension (n) & 38 & 36 & 33 & 33 & 37 & 39 & 24 & 22 & & \\
\hline Diabetes (n) & 6 & 7 & 5 & 5 & 11 & 10 & 1 & 3 & & \\
\hline CAD (n) & & & 8 & 10 & 15 & 17 & 11 & 12 & & \\
\hline Stroke (n) & 4 & 4 & 12 & 9 & 8 & 7 & 1 & 5 & 2 & 5 \\
\hline COPD (n) & 6 & 6 & 5 & 7 & 5 & 7 & 15 & 14 & 2 & 4 \\
\hline CKD (n) & & & 4 & 6 & 17 & 15 & & & & \\
\hline Renal malperfusion ( $\mathrm{n}$ ) & & & & & & & 6 & 7 & 3 & 3 \\
\hline Prior sternotomy (n) & 2 & 1 & & & 9 & 7 & 6 & 5 & & \\
\hline prior cardiac surgery $(n)$ & & & & & & & & & 8 & 6 \\
\hline Emergent surgery $(n)$ & 13 & 10 & 2 & 1 & 5 & 4 & 7 & 7 & 2 & 1 \\
\hline Aortic dissection & 11 & 14 & & & & & & & & \\
\hline Acute & & & 0 & 0 & & & $18 / 274^{*}$ & $3 / 45^{*}$ & & \\
\hline Chronic & & & 0 & 0 & 18 & 20 & & & 3 & 2 \\
\hline \multicolumn{11}{|l|}{ Outcomes } \\
\hline In hospital mortality (n) & 4 & 6 & 1 & 1 & 2 & 2 & 2 & 4 & & \\
\hline 30-day mortality (n) & 2 & 3 & & & 1 & 1 & 1 & 4 & & \\
\hline Operative mortality (n) & 5 & 7 & & & & & 2 & 4 & 0 & 1 \\
\hline New dialysis (n) & & & 1 & 0 & 7 & 3 & 1 & 0 & 1 & 1 \\
\hline $\mathrm{TIA}(\mathrm{n})$ & 4 & 5 & & & & & 0 & 5 & & \\
\hline Permanent stroke $(n)$ & 0 & 5 & 0 & 3 & 1 & 7 & 0 & 3 & 3 & 9 \\
\hline Paraplegia (n) & 2 & 2 & & & 0 & 0 & 1 & 1 & 1 & 2 \\
\hline Reop for bleeding (n) & & & 2 & 3 & 4 & 1 & 3 & 0 & 5 & 4 \\
\hline ICU time (mean, SD) & $21.0 \pm 16.7$ & $12.9 \pm 17.3$ & $4.8 \pm 5.1$ & $1.8 \pm 2.5$ & $6.7 \pm 9.8$ & $2.4 \pm 3.8$ & $4.0 \pm 5.2$ & $8 \pm 13.1$ & $4.5 \pm 1.3$ & $8.5 \pm 10.4$ \\
\hline Hospital LOS (mean, SD) & $29.5 \pm 17.2$ & $27.2 \pm 27.1$ & $32.8 \pm 21.3$ & $27.7 \pm 31.4$ & $21.0 \pm 16.7$ & $12.9 \pm 17.3$ & $12.0 \pm 5.2$ & $15.0 \pm 12.6$ & $33.0 \pm 22.0$ & $38.0 \pm 18.0$ \\
\hline
\end{tabular}

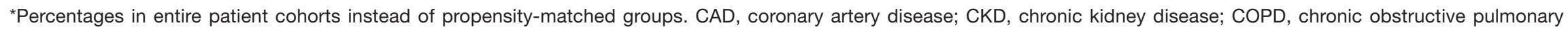
disease; ICU, intensive care unit; LOS, length of stay; LVEF, left ventricular ejection fraction; PVD, peripheral vascular disease; TIA, transient ischemic attack. 
Table S3 Summary of operative techniques used in the included studies

\begin{tabular}{|c|c|c|c|c|c|c|c|c|}
\hline & Concomitant cardiac surgeries & Frozen elephant trunk & CPB use in hybrid procedures & $\begin{array}{c}\text { Total debranching via } \\
\text { sternotomy + TEVAR (zone 0) }\end{array}$ & $\begin{array}{l}\text { Double debranching + TEVAR } \\
\text { (zone 1) }\end{array}$ & $\begin{array}{l}\text { Left Ca-left Sc/Ax bypass or } \\
\text { left-right Ax bypass + TEVAR } \\
\text { (zone 2) }\end{array}$ & $\begin{array}{l}\text { Chimney technique } \\
\text { for zone } 0 \text { repair }\end{array}$ & Other \\
\hline Hiraoka 2017 & & & & $14 / 58(24 \%)$ & $17 / 58(29 \%)$ & $23 / 58(40 \%)$ & $4 / 58(7 \%)$ & \\
\hline Iba 2014 & & & & $8 / 50(16 \%)$ & $30 / 50(60 \%)$ & $6 / 50(12 \%)$ & $5 / 50(10 \%)$ & Bypass to abdominal aorta in 1 case \\
\hline Joo 2019 & & & & $64 / 64(100 \%)$ & & & & \\
\hline Preventza 2015 & $\begin{array}{l}\text { Root, AVR, CABG, tricuspid, MVR, TVR, } \\
\text { PFO repair, Ascending in their open cohort }\end{array}$ & $\begin{array}{l}26 / 274(9 \%) \text { in their } \\
\text { entire open cohort }\end{array}$ & $\begin{array}{l}2 / 25(8 \%) \text { in the matched hybrid cohort } \\
\text { had ascending and root replacement }\end{array}$ & $45 / 45(100 \%)$ & & & & \\
\hline Tokuda 2016 & $\begin{array}{l}3 / 38(8 \%) \text { in their matched open, } 6 / 38 \\
(16 \%) \text { in their matched hybrid cohort } \\
\text { (CABG) }\end{array}$ & & $\begin{array}{l}25 / 38(66 \%) \text { in their matched hybrid } \\
\text { cohort used CPB }\end{array}$ & $46 / 58(79 \%)$ & & & & $\begin{array}{l}12 / 58(21 \%) \text { in the hybrid cohort } \\
\text { underwent type } 3 \text { repair without arch } \\
\text { replacement }\end{array}$ \\
\hline
\end{tabular}

replacement.

\section{0-day Mortality}

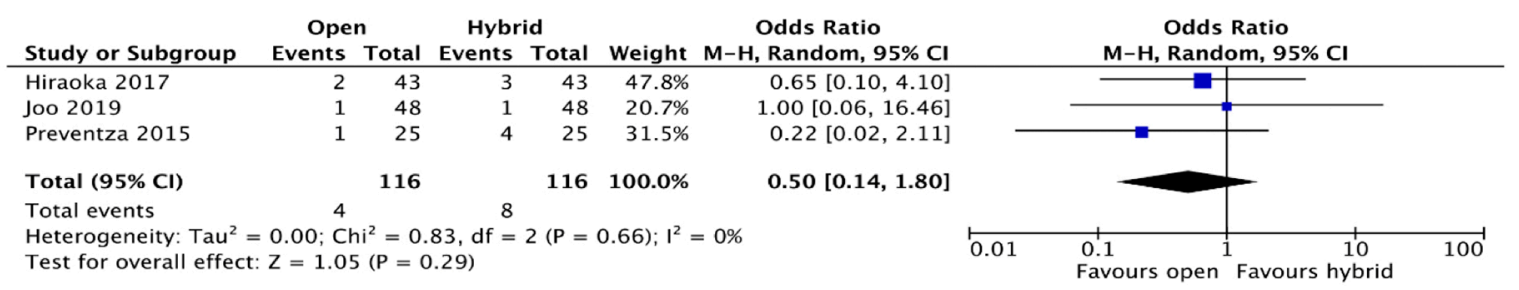

Operative Mortality

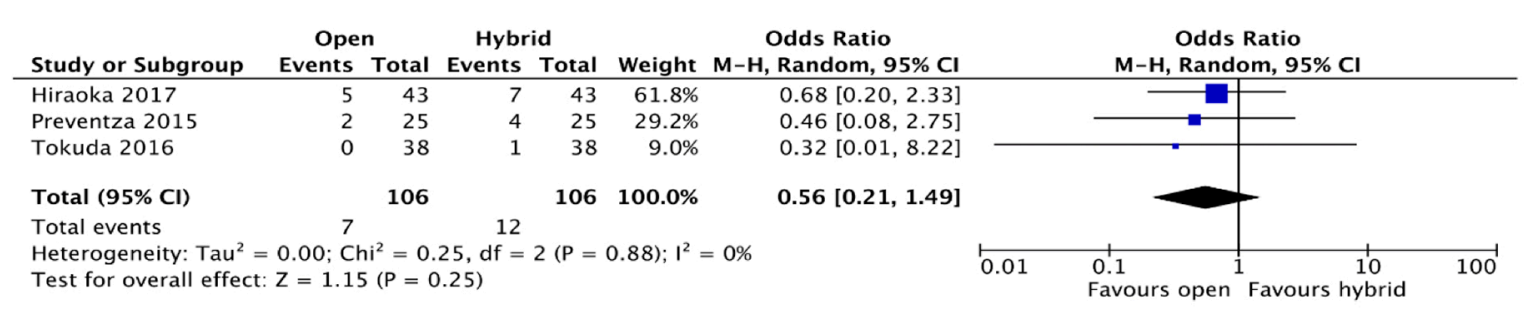

Paraplegia

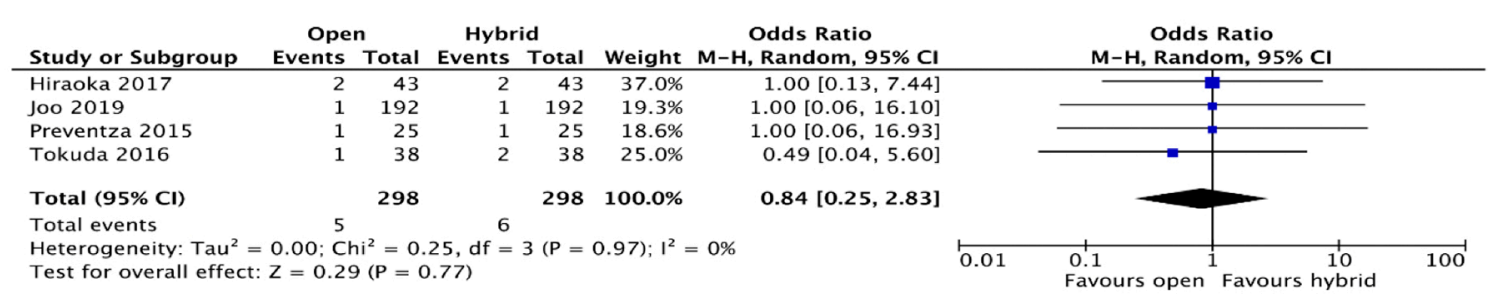

Reoperation for bleeding

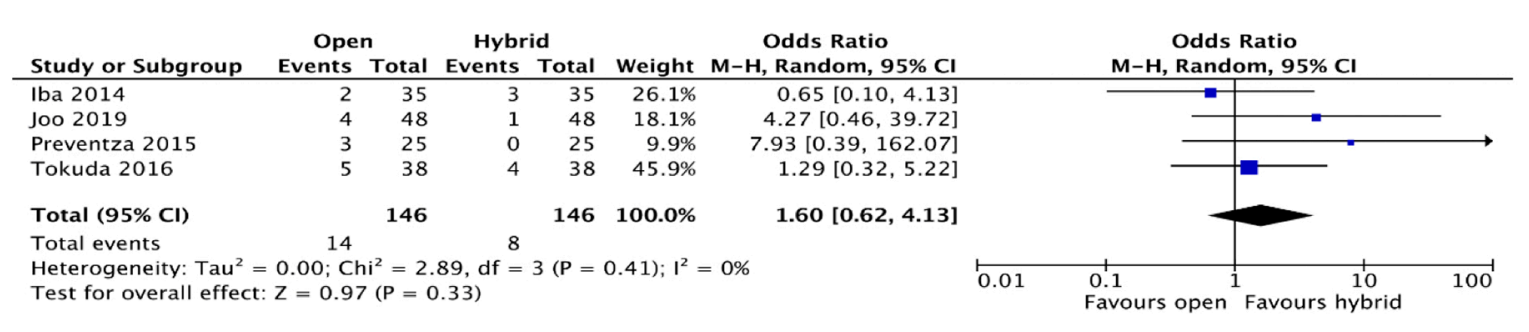

Length of Stay

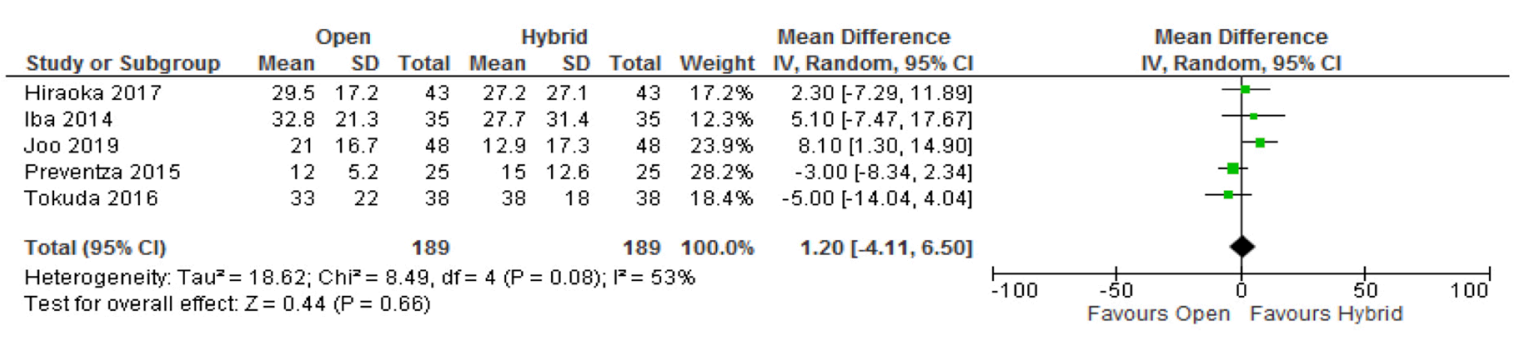

Figure S1 Forest plots for the comparison of outcomes of patients undergoing open versus hybrid aortic arch repair. 


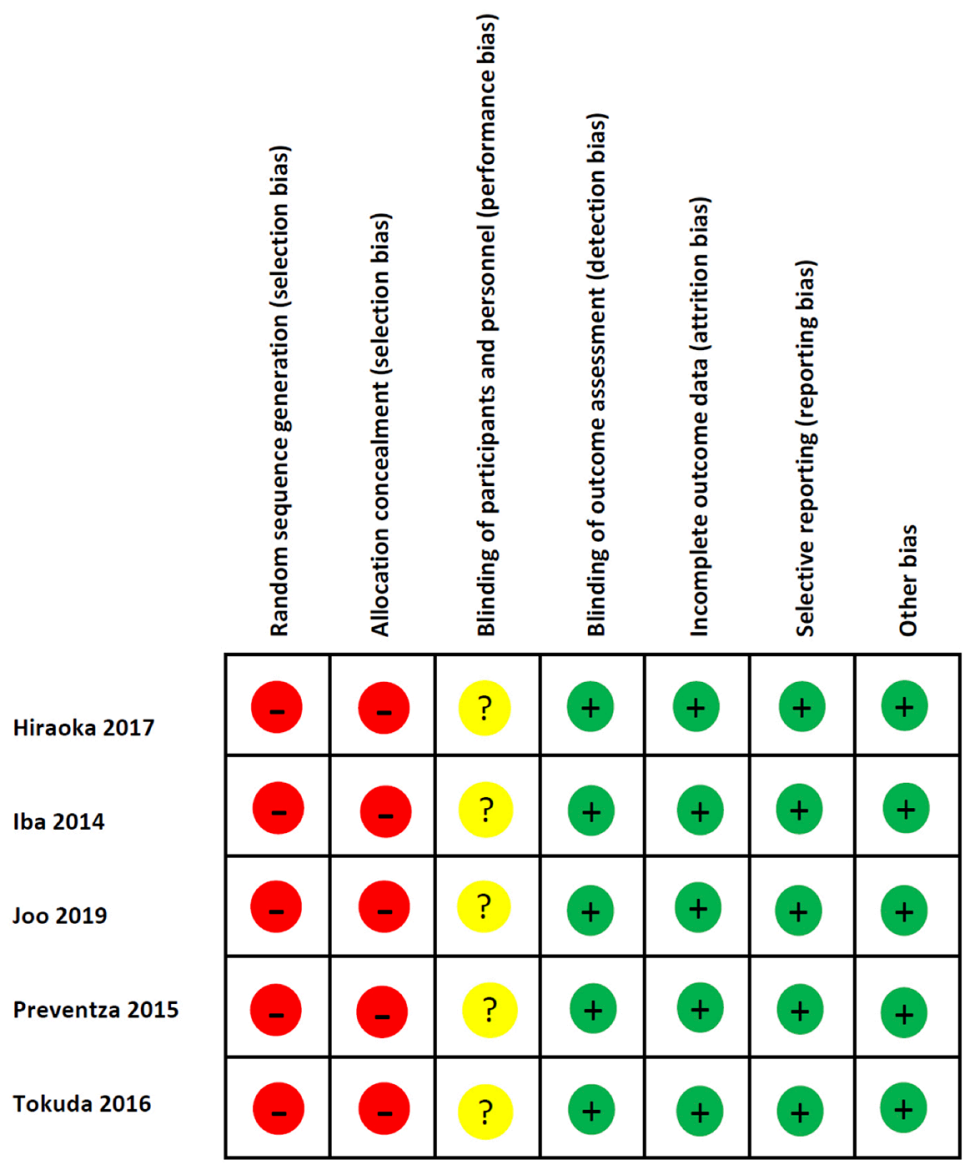

Figure S2 Risk of bias assessment is based on review author's judgement on each included study. Green and red indicate low and high risk of bias, respectively. Yellow indicates unclear risk bias.

A

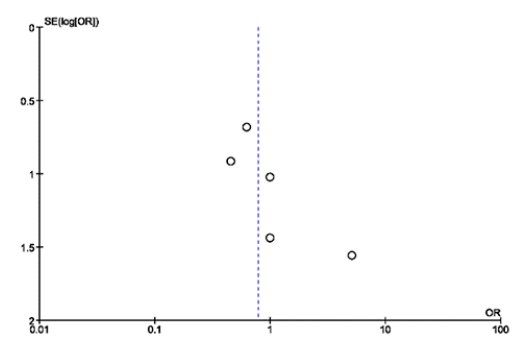

B

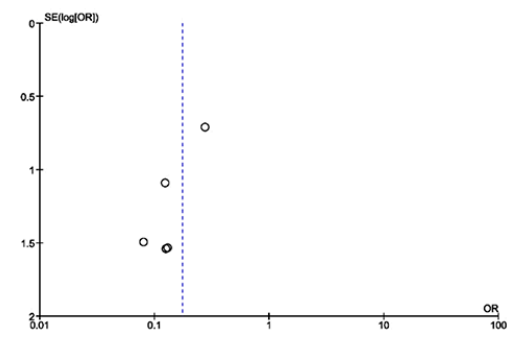

C

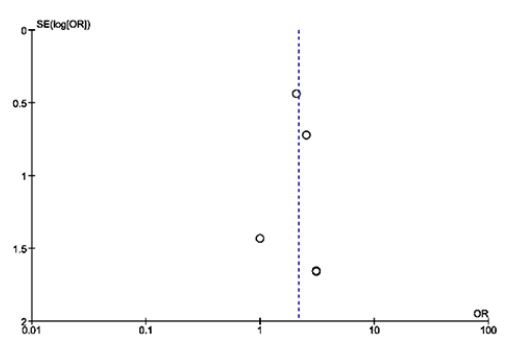

Figure S3 Funnel plots of (A) in-hospital mortality, (B) permanent stroke, and (C) dialysis. OR, odd ratio; SE, standard error. 